\title{
A convergência de linguagens nos especiais do Clarín.com
}

\section{Language convergence in Clarín.com multimedia narratives}

\author{
Raquel Ritter Longhi ${ }^{[a]}$, Mauro César Silveira ${ }^{[b]}$ \\ [a] Doutora em Comunicação e Semiótica pela Pontifícia Universidade Católica de São Paulo (PUC-SP), professora do curso de \\ Jornalismo e do Mestrado em Jornalismo da Universidade Federal de Santa Catarina (UFSC), Florianópolis, SC - Brasil, e-mail: \\ raqlonghi@gmail.com \\ [b] Doutor em História Ibero-americana pela Pontifícia Universidade Católica do Rio Grande do Sul (PUCRS), professor do Departamento \\ de Jornalismo da Universidade Federal de Santa Catarina (UFSC), Florianópolis, SC - Brasil, e-mail: maurocesarsilveira@gmail.com
}

\section{Resumo}

O jornal argentino Clarín tem se destacado por uma história ligada a projetos políticos de seu país, e também, mais recentemente, pela qualidade dos produtos informativos no meio online. Desde que lançou sua versão digital, em 1996, o Clarín.com tem se preocupado com a exploração da linguagem do meio, o que é bastante visível nos chamados "especiais multimídia" que o jornal produz. Este artigo tem o objetivo de analisar esse tipo de formato jornalístico do ponto de vista da convergência de linguagens propiciada pelos meios digitais, uma vez que essa é uma das características, ao lado da interatividade, mais importantes dos novos meios, o que situa o Clarín.com no panorama jornalístico argentino.

Palavras-chave: Especiais multimídia. Clarín.com. Linguagem. Meios digitais.

\section{Abstract}

The argentine newspaper Clarín has posted a bistory linked to the political projects of the country and, more recently, the quality of information products in the online environment. Since it launched its digital version in 1996, the Clarín.com has been concerned with the exploitation of the language of the medium, which is quite visible in the so-called multimedia narratives it produces. This article aims to analyze this type of journalistic format in terms of convergence of languages offered by digital media, since this is one of the most important features of the new media, next to the interactivity, located Clarín.com in argentine journalistic landscape.

Keywords: Multimedia narratives. Clarín.com. Languages. Digital medium. 


\section{O Grupo Clarín e sua trajetória de expansão contínua}

A trajetória do conglomerado de mídia Clarín parte da iniciativa de um político que amargava o ostracismo e alcançou, pouco mais de seis décadas depois, um patamar invejável no mercado mundial de comunicação em língua espanhola. Como ocorreu em muitos países latino-americanos, o grupo foi construído a partir de uma relação convergente entre a empresa jornalística e o poder. ${ }^{1}$ Tudo começou em 28 de agosto de 1945, quando o desacreditado jornalista e ex-ministro Roberto Jorge Noble, um homem conservador que também se dedicava à pecuária de leite, lançou o hoje conhecido tabloide portenho com o claro objetivo de sair da obscuridade. O diário de Buenos Aires seria a base do influente grupo multimídia, apresentando sua primeira edição bem ilustrada e de leitura agradável, com ênfase na cobertura esportiva. A boa receptividade dos leitores estimulou seu crescimento e, em 1963, o Clarín já era o jornal de maior circulação na capital argentina. Quatro anos depois, com o fechamento do pioneiro tabloide daquele país, o El Mundo, a tiragem saltou de 347 mil para 424 mil exemplares e a publicação adquiriu um caráter inovador, lançando a primeira revista semanal como encarte de um jornal diário.

A morte do fundador, em 1969, não diminuiu o ritmo de expansão do grupo. Pelo contrário: herdado pela viúva de Roberto, Ernestina Herrera de Noble, a empresa continuou crescendo, atingindo seu ritmo mais intenso entre o fim da década de 1980 e o início dos anos 1990, quando diversificou suas atividades por meio de um profundo endividamento em dólares. Nessa época, o banco norte-americano de investimentos Goldman Sachs pagou US\$ 500 milhões para adquirir 18\% do grupo. ${ }^{2}$ Antes disso, teve papel importante na evolução do Clarín, o vicepresidente e atual sócio Héctor Horacio Magnetto. Com carta branca de Ernestina, ele adotou uma gestão desenvolvimentista nos negócios e, em pouco tempo, a organização figurou entre as dez maiores empresas da Argentina e os três maiores grupos de mídia da América Latina - o segundo da América do Sul.

No entanto, esse êxito não foi marcado apenas pela competência administrativa. Como observa Barreto (1999, p. 65), esse contador e dirigente de uma concessionária de veículos valorizou a prática de troca de favores com o poder político e econômico, tirando muito proveito disso.

Junto com o staff que se apodera dos controles tanto da administração quanto da redação do jornal, surge Héctor Magnetto, o personagem responsável pela guinada administrativa por Ramos $^{3}$ (1993, p.118-119) - e ideológica - da empresa, criticado por suas alianças com todos os governos civis e militares posteriores. Dessas relações vai emergir a faceta monopólica do grupo e sua futura feição multimídia através da incorporação da manufatura papeleira PapelPrensa e, no final dos anos 80, com a absorção da Rádio Mitre e do Canal 13, entre outras vantagens. É o início da fase Magnetto na história do jornal e do emergente Grupo Clarin (BARRETO, 1999, p. 65).

Essas conquistas são apenas as mais visíveis dos inúmeros favores e benesses obtidos pelo jornal e pelo grupo, assegurando sua hegemonia nos meios de comunicação argentinos. Depois de assumir a feição

1 No século XIX, uma conjugação de avanços técnicos permitiu que as publicações impressas se expandissem, com vigor, em todos os continentes, sobretudo na Europa e nos Estados Unidos. Havia, contudo, uma diferença gritante entre os grandes jornais europeus, particularmente da França e da Inglaterra, e os latino-americanos: o grau de independência. Com honrosas exceções, as publicações lançadas no chamado Novo Mundo estavam vinculadas diretamente ao governo. Na Argentina, por exemplo, despontava o La Nación, fundado em janeiro de 1870 pelo general Bartolomeu Mitre, presidente da então Confederação Argentina, que fazia questão de publicar artigos e comentários de seu interesse. Ainda hoje, na sua página de opinião, logo acima do editorial, essa publicação secular destaca sua origem, reproduzindo o anúncio da proposta editorial de seu primeiro número ("La Nación será una tribuna de doctrina"), e apresenta como seu diretor o fundador Bartolomeu Mitre. No Brasil, ainda prevalece o tradicional enlace entre o jornalismo e o poder político e econômico, ressalvadas as vozes dissonantes de cada período histórico. Sintomaticamente, o primeiro jornal editado no país, a Gaz̧ta do Rio de Janeiro, nasceu graças à instalação da Imprensa Régia, em 1808, depois da chegada de D. João VI.

2 Os outros $82 \%$ das ações pertencem ao grupo diretor formado por Héctor Horacio Magnetto, Ernestina Herrera de Noble, José Aranda e Lucio Pagliaro.

3 RAMOS, J. A. Los cerrojos a la prensa. Buenos Aires: Amfin, 1993. Sobre o Clarín ver também: RAMOS, J. A. El periodismo atrasado. Buenos Aires: Fundación Gada, 1996. 
multimídia, o conglomerado investiu em suportes de ponta, como internet, TV a cabo e via satélite e telefonia móvel, assumindo a liderança argentina também nesses setores. Da extensa lista de atividades da empresa, Albornoz (2007, p. 124) registra que o Clarín é o principal jornal argentino e o de maior circulação no mundo de fala espanhola - com uma tiragem média superior a 550 mil exemplares e mais de dois milhões de leitores diariamente - e destaca outros veículos bem-sucedidos, como o diário esportivo Olé e o site jornalístico Clarín.com, ambos lançados em 1996. O grupo empresarial ainda detém uma grande produtora de cinema e a maior fábrica de papel do país (numa parceria com o grupo $L a$ Nación e o próprio governo argentino). No site www. clarinnegocios.com.br, o conglomerado apresentouse, em 2009, como "o maior grupo de comunicação em língua espanhola do mundo" e informou que atualmente possui 26 empresas e emprega mais de 13.600 funcionários, além de negociar ações nas bolsas de Londres e Buenos Aires há dois anos.

Recentemente, o conglomerado exibiu mais uma vez sua tradicional eficiência na relação com o poder político e econômico. Durante a presidência de Néstor Kirchner, o bom comportamento dos veículos do grupo foi recompensado com a renovação por mais dez anos de todas as suas licenças de rádio e televisão, "sem qualquer discussão", como denuncia o professor Gustavo Martínez Pandiani (PINHEIRO, 2008), da Faculdade de Comunicação Social da Universidad del Salvador, em Buenos Aires. Além disso, a empresa abocanhou nada menos que o equivalente a 22 milhões de reais em propaganda oficial entre 2003 e 2006, como revela o livro Propaganda K: una maquinaria de promoción con el dinero del Estado, da jornalista Maria O'Donnell. Entre abril e maio de 2008, quando o Clarín acabou sendo obrigado a abrir generosos espaços para os protestos dos produtores rurais, indignados com o aumento do imposto sobre a exportação de grãos decretado pela presidenta Cristina Kirchner, o governo argentino sentiu-se traído e ameaçou retaliar com algumas medidas, como o limite do número de concessões públicas e o estabelecimento de um teto de $30 \%$ de capital estrangeiro nas empresas de comunicação. Depois de um jogo de escaramuças, a paz foi selada numa reunião entre diretores do jornal e a presidenta, na Casa Rosada. A manchete do Clarín do dia seguinte era mais do que reveladora: "Cristina quer dialogar: há conversa com o campo".
Essa trégua teve fim às vésperas das eleições do Congresso, ocorridas em 28 de junho de 2009. $\mathrm{Na}$ semana decisiva, em que cerca de 28 milhões de argentinos iriam escolher os seus legisladores e decidir se o governo " $K$ " perderia a maioria no Congresso o que de fato aconteceu, pois os candidatos oficiais obtiveram apenas $30 \%$ dos votos no âmbito nacional e a situação perdeu 22 cadeiras de deputados -, o conhecido jornalista portenho Daniel Santoro, editor do caderno "País" do Clarín, falou a Paul Alonso, do Knight Center for Journalism in the Americas, da Universidade do Texas, entre outras coisas, sobre as difíceis relações dos Kirchner com a imprensa. O distanciamento não foi só provocado pela relutância da presidenta em conceder entrevistas coletivas, mas também por suas frequentes críticas às entidades representativas dos jornalistas e empresários de mídia. Três elementos têm sido decisivos para esse novo momento de tensão: o uso mais vigoroso da publicidade estatal pelo governo para recompensar ou castigar linhas editoriais, as pressões fiscais e uma polêmica lei de radiodifusão, abrindo o setor à privatização.

Para Santoro (2009), o clima eleitoral, marcado também pelo debate da liberdade de imprensa, agravou o quadro.

A situação piorou. O governo divulgou a existência de um projeto de lei de radiodifusão em plena campanha que, se aprovado, prejudicará o grupo Clarin e outros grupos de comunicação na Argentina. O projeto deixaria a empresa espanhola Telefónica ingressar no mercado. Nenhum grupo midiático argentino pode competir com a escala financeira da Telefónica da Espanha, e a lei de privatizações da época de Menem proibe as empresas de serviços públicos de comprar meios de comunicação.

Após a derrota nas eleições de junho, essa ameaça foi concretizada, aumentando o grau de tensão entre os dois lados em confronto. Aproveitando a anterior maioria governista no Congresso - a nova composição, desfavorável à presidenta Cristina Kirchner, tomou posse apenas em dezembro -, a presidenta conseguiu a aprovação no Senado, em 10 de outubro de 2009, da Lei de Serviços Audiovisuais, que obriga os grupos de mídia do país a uma redução forçada dos seus negócios. A nova regulamentação impõe limites quantitativos à propriedade de 
emissoras de rádio e TV, impede que um mesmo concessionário tenha canais de televisão aberta e a cabo, fixa teto de assinantes para os operadores de cabo e estabelece cotas de programação nacional, entre outras medidas, assim como um limite de $33 \%$ do total de concessões para empresas com fins lucrativos. Os outros dois terços passam a ser destinados ao Estado e a ONGs, como sindicatos e universidades.

Mesmo que não ocorra uma reaproximação entre o poderoso conglomerado e o governo argentino, determinando o acerto de um novo período de trégua - o que parece improvável depois das medidas adotadas -, não há indícios de que a infraestrutura dos veículos do grupo seja abalada, pelo menos em curto prazo, na medida em que as empresas têm um ano para se adaptarem aos termos da nova lei. O êxito do portal Clarín.com devese, evidentemente, à força econômica da empresa. Mantendo-se na contramão da tendência mundial pela convergência com o impresso até 2008, quando a direção do complexo de mídia optou, finalmente, pela integração das duas redações, o site de notícias mantém uma proposta jornalística com elevado grau de autonomia e que foi aprofundada na sua última reforma editorial, deflagrada em outubro de 2007. Lançado em 10 de março de 1996, o Clarín.com reúne cerca de 80 profissionais - 70 jornalistas e 10 da área de Informática. A produção exclusiva já atinge $80 \%$ do que é divulgado no portal, invertendo a proporção inicial, que contava com apenas $20 \%$ de matérias próprias. "Quando as redações se integram, uma delas perde, e ao afirmar a independência do online evitamos qualquer risco", sustentava o diretor geral do Clarín.com, Marcelo Franco (2007), ${ }^{4}$ na época da recomposição editorial, quando ainda não se cogitava uma atuação conjunta entre site e diário de papel.

Bem antes dos planos de reestruturação, que apontavam para a necessidade da integração com o jornal, já havia, contudo, uma regular colaboração entre os veículos do mesmo grupo empresarial. Desde
2006, todos os dias, entre 12 e 13 horas, um editor da seção "Últimos momentos", do meio online, participa da reunião de pauta na redação do Clarín impresso, acompanhando os principais fatos que receberão a cobertura do tradicional diário de Buenos Aires. “Também promovemos etapas de fusão, através da realização de seminários, e o chamado intercâmbio cultural, que é um dia de trabalho de dois editores de papel aqui no digital ou vice-versa, estimulando que alguns profissionais do impresso possam se adaptar e produzir para o Clarín.com", ressalva Pedro Irigoyen (2007), um dos produtores do site. Na reforma estrutural de outubro de 2007, o Clarín.com apresentou uma arquitetura reelaborada e um desenho renovado e consolidou seu caráter multimídia, já notabilizado pelos seus especiais, por meio da multiplicação da oferta de blogs e de um player de vídeos noticiosos no topo da página. Outro objetivo das mudanças foi permitir que o internauta pudesse aceder com maior velocidade aos conteúdos disponíveis e aos serviços oferecidos, como sintetiza o jornalista Horacio Bilbao (2007), editor de "Videonotas" do portal: "Se renovam os serviços de clima e trânsito agora com mapas e atualização imediata. Reaparecem os rankings com as notas mais lidas, as mais recomendadas e as mais comentadas, e se redobra a aposta pela multimídia do site, uma tendência que cresce sem limites no universo online. O usuário do Clarín.com encontra agora uma oferta renovada, em que a velocidade, a facilidade de acesso, a produção multimídia e a participação dos leitores ganha cada vez mais relevância".

A busca da "multimidiatização genuína", como ressalta o diretor Marcelo Franco (2007), é acompanhada por mais um objetivo ambicioso: depois de inverter de 20 para $80 \%$ a relação da produção exclusiva diante do material de outras empresas do grupo empresarial, como os vídeos do Canal 13, que ainda são veiculados na primeira página do portal, ele pretende ver lançada na rede apenas produção própria do jornal online. "Queremos atingir 100\% logo, logo", afirma Franco (2007), prevendo que, em pouco tempo, os parceiros do conglomerado ficarão

\footnotetext{
4 As declarações sobre a reforma editorial de 2007 que constam neste texto, tanto de Marcelo Franco quanto de Pedro Irigoyen e Horacio Bilbao, foram obtidas durante entrevistas realizadas por um dos coautores do presente artigo, Mauro César Silveira, durante as atividades do projeto de pesquisa "Clarín.com e as possibilidades de convergência entre o jornalismo impresso e o jornalismo digital". O trabalho foi viabilizado por meio de uma bolsa de pesquisa do Programa de Mobilidade Acadêmica Escala Docente, para intercâmbio acadêmico de professores e pesquisadores entre as instituições de ensino superior da Associação de Universidades Grupo Montevideo (AUGM), e contou com o apoio da Faculdade de Ciências da Comunicação da Universidade de Buenos Aires (UBA)
}

Rev. Estud. Comun., Curitiba, v. 11, n. 25, p. 157-166, maio/ago. 2010 
limitados aos links e às colaborações especiais. Hoje, apenas a capa e as principais manchetes do Clarín de papel podem ser visualizadas livremente no site. A edição integral do impresso só pode ser acessada, em alta resolução, por meio do pagamento de uma assinatura mensal de US\$17,50.

Obtida a autonomia de produção, o próximo passo será na direção da maior velocidade possível, o que implica matérias curtas e aumento das transmissões ao vivo. O futuro do Clarín.com, de acordo com as ideias concebidas por Marcelo Franco, será marcado essencialmente pelo absoluto equilíbrio em três tipos de produções noticiosas, sem prejuízo dos seus elogiados especiais multimídia. Aliás, esses premiados trabalhos, que apresentam reportagens que exploram, de forma intensa e competente, os recursos de hipermídia, continuam sendo o grande diferencial do portal, contribuindo para a consolidação de uma linguagem integradora na web, como veremos mais detidamente na sequência deste texto. A tendência é que os especiais multimídia sejam ainda mais valorizados, sobretudo após os números mais recentes sobre o avanço da internet na Argentina, acessada por 15.600 .000 pessoas, de acordo com dados divulgados pela empresa D'Alessio IROL em julho de 2008. Nesse universo em crescimento, de acordo com a mesma pesquisa, o Clarín.com viu sua liderança entre os meios digitais crescer 10 pontos, subindo de $79 \%$, em 2006, para 89\%. ${ }^{5}$

\section{Multimídia e Flash Journalism}

Em quase 15 anos de jornalismo online, as possibilidades multimídia dos meios digitais, que permitem a integração de imagens, sons e texto verbal simultaneamente, têm sido exploradas de forma crescente, fato que se deve ao avanço da velocidade de conexão e de capacidade de armazenamento da rede de computadores, e ao desenvolvimento de softwares, como o Adobe ${ }^{\circledR}$ Flash Player.

Numa definição que se convencionou chamar de Flash Journalism (McADAMS, 2005), os produtos informativos em Flash ${ }^{\circledR}$ parecem ter tomado conta do cenário do jornalismo nos meios digitais.
Grande parte dos especiais multimídia desses meios são produzidos com esse software, que permite colocar, em um mesmo pacote, arquivos de texto, imagens e sons em formatos executáveis. Isso resulta em maior dinamicidade e agilidade, uma vez que permite distribuir várias mídias diferentes sem a necessidade de fazer download de programas específicos para rodá-las (McADAMS, 2005).

Em seu trabalho sobre a reportagem nos meios digitais, Larrondo Ureta (2004, p. 5) discorre sobre a "reinvenção" do formato reportagem, no jornalismo online, proporcionada pela hipermídia. Para a autora, "a chegada de uma nova modalidade textual como o hipertexto informativo reconfigura os gêneros jornalísticos tal e como o conhecemos no meio impresso". A reportagem hipertextual então, para ela, seria "uma modalidade que está em busca de sua especificidade em um relato não sequencial e multimídia" (LARRONDO URETA, 2004, p. 9). A compreensão de tais especificidades passa pelo entendimento e aprofundamento nas questões relativas à convergência de linguagens propiciadas pelos meios digitais. Dois conceitos vêm colaborar nesse entendimento, o de multimidialidade por integração (SALAVERRÍA, 2005) e o de intermídia (LONGHI, 2008).

Salaverría observa que o uso da multimidialidade nos cibermeios atuais pode ser considerado como muito modesto. A maioria daqueles que se apresentam como "multimídia" em realidade oferecem apenas textos, imagens e sons que se podem consumir de maneira separada ou consecutiva. Somente alguns, para o autor, precisamente aqueles de vanguarda, começaram a experimentar com a combinação desses elementos multimídia em um único discurso (SALAVERRÍA, 2005, p. 57-58). ${ }^{6} \mathrm{O}$ autor salienta que os webjornais utilizam a multimídia em dois aspectos diferentes: por justaposição, quando os elementos (textos, imagens e sons) estão colocados lado a lado, desagregadamente (SALAVERRÍA, 2005, p. 58), e por integração, quando tais elementos são reunidos no mesmo suporte e possuem unidade comunicativa, articulados em um discurso único e coerente.

Já o autor português João Canavilhas (2007, p. 7), ao propor um modelo para a webnotícia, aponta

\footnotetext{
5 Cabe observar que a pesquisa mencionada oferecia a possibilidade de respostas múltiplas à pergunta: "Qual o diário online que você visitou nos últimos 15 dias?". Assim, o segundo colocado, o La Nación.com saltou de 54\% para $62 \%$ no mesmo período. O terceiro portal mais visitado, o Infobae, também cresceu: de 30\% para 44\%.

6 Tradução nossa.
} 
para a flexibilidade e a dinamicidade das narrativas hipermidiáticas na web, caracterizadas por três conceitos-chave: hipertextualidade, multimidialidade e interatividade. $\mathrm{O}$ autor avalia tais especificidades em sua relação com a personalização da notícia e com a configuração de uma linguagem própria do meio, apontando, entretanto, que, sendo um fenômeno recente, o webjornalismo não tem modelos estáveis para a notícia (CANAVILHAS, 2007, p. 9). Ele aponta, porém, para a existência de uma linguagem webjornalística com características muito peculiares, ao utilizar códigos de todos os meios de comunicação.

Convergência tem sido um conceito-chave para entender as transformações por que passa a linguagem nos meios digitais. Ela define o atual estado da arte não somente dos formatos jornalísticos, mas de diversas manifestações da comunicação hipermidiática. Dois aspectos, que se relacionam entre si, devem ser levados em conta na análise da convergência: a combinação de linguagens e a remodelação de meios, porintermédio de sua hibridação. Roger Fidler (1998), com o conceito de mediamorfosis, definia o processo de complementaridade e coevolução dos meios. Outros autores, desde McLuhan, na década de 1960, apontam para esses processos mediamórficos. Tais estratégias de combinação e arranjos são indicadas como essenciais para a configuração de uma linguagem própria dos novos meios.

Quando se fala em hibridação de meios, está implícita a instância da linguagem. Para Machado (2007), é hora de apostar na ideia de convergência como a melhor alternativa para se pensar os meios no campo da comunicação. Isso porque no interior de cada meio há conflito, embate, surgimento de novas tendências e movimentos antagônicos.

No ambiente multimidiático da hipermídia, a convergência de mídias tem implicação direta nas linguagens dos produtos jornalísticos. As nomenclaturas variam: termos como "conteúdos multimídia", "multimídia", "especiais multimídia", "interactive graphics", "fotorreportajes", "especiales", "interactive narratives", dentre outros, são usados pelos sites de notícias para definir formatos que se aproveitam das possibilidades de disponibilização de arquivos de texto, imagens e/ou sons simultaneamente e podendo ser acessados de forma multilinear e interativa. O conceito de multimídia, entretanto, não parece ser suficiente para dar conta desses formatos, uma vez que o mesmo está muito mais relacionado aos conteúdos do que com a maneira como tais conteúdos são integrados.

Nesse sentido, a concepção de intermídia desenvolvida por Longhi (2008) vem colaborar para o entendimento das estratégias de convergência de linguagens, que vão além da simples colagem, para efetivar-se numa fusão que opera conceitualmente, no nível do seu significado. ${ }^{7}$

Ao verificar as passagens da linguagem nos meios digitais, nos quais o trânsito de signos por diferentes suportes produz novos signos e, assim, linguagens renovadas, Plaza (2001) apontava para o termo intermídia como um processo de hibridação de linguagens que operava pela síntese qualitativa.

Tanto multimídia como intermídia são categorias interdisciplinares que, como colagem ou síntese-qualitativa, colocam em questão as formas de produção-criação individual e sobretudo a noção de autor. [...] os meios tecnológicos absorvem e incorporam os mais diferentes sistemas sígnicos, traduzindo as diferentes linguagens históricas para o novo suporte. Essas linguagens transcodificadas efetivam a colaboração entre os diversos sentidos, possibilitando o trânsito intersemiótico e criativo entre o visual, o verbal, o acústico e o tátil (PLAZA, 2001, p. 66).

O autor, verificando o potencial do computador como meio de combinação de linguagens, desenvolveu aideia de "transmutações intersígnicas", para dar conta de tais rearranjos e da ausência de demarcação das fronteiras entre os diversos sistemas sígnicos. Assim, segundo Plaza (2001), o verbal, o pictórico, o fotográfico, o fílmico, o televisivo, o gráfico e o musical, entre outros, são levados em conta na sua combinação como transdução, que estaria pautando o desenvolvimento dos meios tecnológicos. Ele observou, ainda, tais processos em duas vertentes: o que estava se configurando como multimídia, composta de uma simples colagem de linguagens, e como intermídia, definida como síntese qualitativa

Segundo Higgins (1984), o embasamento da intermídia está na fusão conceitual de meios distintos entre si que, conjugados no nível de seu significado, formam um terceiro meio, diferente dos anteriores. 
da hibridação de meios. A noção de intermídia, que hoje aparece na concepção de convergência, para Plaza (2001), está bastante ligada a tais movimentos por diferentes suportes, como um aspecto que os diferencia de tudo o que vem antes.

O conceito de intermídia pode dar conta da fusão conceitual operada pelas estratégias de remodelação de meios e linguagens que marcam os produtos digitais. Intermídia seria um modo de olhar para tal aglutinação, que vai além da simples colocação dos elementos na tela do computador: traduz-se mais pela combinação conceitual, pela mistura de meios que, ao se mesclarem, mantêm algumas características e adquirem outras, produzindo formatos específicos de linguagem.

Uma vez que podemos entender o especial multimídia como uma espécie de herdeiro da grande reportagem do impresso, e verificando o quadro classificatório proposto por Noci e Salaverría (2003) para os gêneros do webjornalismo (apud DÍAZ NOCI; PALACIOS; 2009a, p. 24), uma melhor classificação definiria o especial multimídia dentro da categoria "gêneros interpretativos". Por outro lado, deve-se levar em conta que, dentro do que se entende por especial multimídia, aparecem formatos tão diversos como entrevistas, depoimentos, documentários, todos eles, classificáveis, segundo as teorias canônicas do jornalismo, como gêneros. Estes podem ser entendidos como "modelos textuais caracterizados por certas convenções estilísticas e retóricas" (DÍAZ NOCI; SALAVERRÍA, 2003, p. 39; SALAVERRÍA, 2004 apud BERTOCCHI, 2005). Trata-se de "diferentes modalidades da criação lingüística destinadas a serem canalizadas por qualquer meio de difusão coletiva e com o ânimo de atender a dois dos grandes objetivos da informação de atualidade: o relato de acontecimentos e o juízo valorativo que provocam tais acontecimentos" (ALBERTOS, 1992, p. 213-392 apud BERTOCCHI, 2005).

\section{O caso do Clarín.com}

Desde que lançou sua versão digital, em 1996, o Clarín tem se preocupado com a exploração da linguagem do meio, o que é bastante visível nos chamados "especiais multimídia" que produz. Este artigo tem o objetivo de analisar esse tipo de formato jornalístico do ponto de vista da convergência de linguagens propiciada pelos meios digitais, uma vez que essa é uma das características mais importantes dos novos meios, ao lado da interatividade, localizando o Clarín.com no panorama jornalístico argentino.

Embora a exploração de linguagens dos meios digitais seja uma aposta do grupo Clarín, como consta na sua página na internet, ${ }^{8}$ a integração das redações impressa e online ainda não teve efeitos na produtividade no que diz respeito ao destaque concedido aos formatos multimídia. O fato foi comentado pelo jornalista Horacio Bilbao (2007), em entrevista concedida por e-mail aos autores. ${ }^{9}$

$\mathrm{Na}$ redação do jornal online, há uma equipe fixa de desenvolvimento de especiais que não foi transferida para a redação do impresso, o que dificulta a integração, de acordo com Bilbao (2007). Em geral, a maioria dos especiais do Clarín.com contam com um jornalista ou uma equipe de jornalistas dirigindo-os e uma equipe, encarregada de contar as histórias com ferramentas multimídia, formada por oito pessoas, designers especializados no software Flash, em animação, e um técnico encarregado do som.

No Clarín.com, ${ }^{10}$ verifica-se uma opção editorial pelos especiais multimídia, famosos pela quantidade de prêmios de jornalismo que têm recebido nos últimos anos: ${ }^{11}$ esses produtos contam com uma seção própria, "Especiales Multimedia", ${ }^{12}$ que apresenta, além dos especiais propriamente ditos, fotorreportajes constituídos por slide-shows com áudio, narração em offe/ ou música. O especial, dessa forma, tem seu lugar em seção própria, a ele destinado, como

\footnotetext{
8 Ver: http://www.grupoclarin.com/

9 "Más que una cuestión editorial, resulta un olvido imperdonable. Pero supongo que tiene que ver con ciertas políticas de medios, que atienden más el último momento (breaking news) que los contenidos propios. Hemos hecho varios pedidos para tener una presencia de producciones y trabajos de investigación en la portada, pero los ritmos de cualquier modificación de este tipo van a contramano de la flexibilidad que debería permitir un sitio de Internet”. Citado em LONGHI, 2009.

${ }^{10}$ Ver: http://www.clarin.com/

${ }^{11}$ Desde 2002, quando "Piqueteros, la cara oculta de um fenómeno" recebeu o prêmio da Fundación Nuevo Periodismo Iberoamericano, os produtos multimídia do Clarín têm recebido diversos prêmios internacionais de jornalismo e design.

${ }^{12}$ Ver: http://www.clarin.com/diario/especiales/index.html
} 
uma vitrine onde se dá a exploração da multimídia e da criatividade jornalística na conformação de um gênero que caminha em busca de sua independência dentro da estrutura noticiosa do site.

Dentre os conteúdos, destacam-se a guerra contra as drogas ("Ay México lindo, la narcoguerra"); a corrida presidencial norte-americana nas eleições de 2008 ("Ruta 66"); as migrações sociais ("Cayucos", ganhador do prêmio da Society for News Design em 2009); datas históricas como os 25 anos da Guerra das Malvinas ("Malvinas 25 anos, una herida abierta"), também premiado, com o The Communicator Awards. ${ }^{13}$ Grande parte desses produtos tem à frente de sua produção, o jornalista Gustavo Sierra, correspondente internacional do periódico, que atua tanto na roteirização como na produção e captura de materiais para os especiais.

O especial multimídia poderia ser classificado como um novo gênerojornalístico, mais especificamente um gênero do jornalismo online. Em artigo anterior, levando em conta tal designação, sugerimos uma definição para esse formato:

grande reportagem constituída por formatos de linguagem multimídia convergentes, integrando gêneros como a entrevista, o documentário, a infografia, a opinião, a crítica, a pesquisa, dentre outros, num único pacote de informação, interativo e multilinear (LONGHI, 2009, p. 5).

Entendemos como formatos de linguagem multimídia convergentes aqueles compostos por linguagem textual, sonora e/ou visual, como arquivos de imagens em movimento e estáticas, representação textual e arquivos de som. São convergentes por estarem dispostos de modo integrado, ou seja, em uma mesma janela e apresentando unidade informativa ou coesão, conforme Salaverría (2005). Já o conceito de "pacote de informação", é utilizado aqui como um conjunto informativo configurado com um software específico, como o Flash, segundo McAdams (2005).

No Clarín.com, destacam-se como características dos produtos multimídia, em relação à sua linguagem convergente: sons (ambiente ou música) nas fotorreportagens (slide-shows) e, nos especiais multimídia, variados formatos dentro de um grande produto. Assim, vê-se, por exemplo, em "En la tierra del Diego", ${ }^{14}$ uma divisão em duas partes: "Hambre y marginalidad", com vídeos diferentes acerca dessa temática, e "Problemas y soluciones", disponibilizando vídeos e infografias interativas. As imagens funcionam, nesse sentido, como um mosaico do qual se pode partir para a navegação pelos vídeos, tanto de moradores do local retratado, a cidade de Ilha Fiorito, como de especialistas entrevistados, que fornecem "soluções" aos problemas.

A convergência efetiva-se não apenas na utilização de linguagens e formatos combinados para uma narrativa mais plural, caso da conjugação de imagens estáticas e em movimento, textos e sons, como também por meio da convergência entre ferramentas da própria Web 2.0. Aproveitando-se da possibilidade de maior participação entre produtores e consumidores e da troca de conteúdos na internet por meio de blogs e redes sociais, o Clarín criou uma seção destinada unicamente a isso. ${ }^{15}$ Assim como vários outros especiais multimídia produzidos pelo jornal, "En la tierra del Diego" inclui outras formas de contato com os leitores e, ao mesmo tempo, com a sua própria produção, como no caso dos links para o blog, ${ }^{16}$ para o Twitter ${ }^{17}$ e o Facebook. ${ }^{18}$

\section{Considerações finais}

O conceito de convergência tem sido usado para definir o atual estado da arte, não somente dos formatos jornalísticos, mas de diversas manifestações da comunicação hipermidiática. No caso da pesquisa aqui apresentada, verificou-se o chamado "especial multimídia" dentro do quadro de convergência de linguagens proporcionado pelas linguagens digitais e sua inserção num jornal online de importância indubitável no contexto do jornalismo latino-americano, caso do Clarín.com.

\footnotetext{
13 Todos com acesso a partir do link: http://www.clarin.com/diario/especiales/

14 Ver: http://www.clarin.com/diario/2009/11/23/conexiones/home.html

${ }^{15}$ Ver: http://blogs.clarin.com/

${ }^{16}$ Ver: http://blogs.clarin.com/enlatierradeldiego/

${ }^{17}$ Ver: http://twitter.com/MultimediaTeam

${ }^{18}$ Ver: http:/ /www.facebook.com/profile.php?id=1697362954\&ref=ts
} 
Por meio de entrevistas com profissionais daquele órgão de imprensa, concluímos que, embora a exploração de linguagens dos meios digitais seja uma aposta do grupo Clarín, aproveitando sua condição de maior conglomerado de mídia da Argentina - agora ameaçado pela recente Lei de Serviços Audiovisuais -, a integração das redações impressa e online, principalmente no que diz respeito ao destaque concedido aos formatos multimídia, ainda não teve efeitos consideráveis. Apesar disso, o periódico tem se destacado na produção dos especiais multimídia, no que diz respeito à convergência de linguagens.

\section{Referências}

ALBORnOZ, L. A. Periodismo digital: los grandes diarios en la red. Buenos Aires: La Crujía, 2007.

BARRETO, H. R. Clarín: de coadjuvante a líder. A trajetória do jornal que se transformou no maior grupo multimídia da Argentina e segundo no mundo hispânico. 1999. 147 f. Dissertação (Mestrado em Comunicação Social) - Universidade Metodista de São Paulo, São Bernardo do Campo, 1999.

BERTOCCHI, D. Gêneros jornalísticos em espaços digitais. Actas da SOPCOM, 2005. Disponível em: <http:/ / bocc.ubi.pt/pag/bertocchi-daniela-generos-jornalisticosespacos-digitais.pdf $>$. Acesso em: 30 jun. 2009.

BILBAO, H. Horacio Bilbao: inédito. Buenos Aires: [s.n.], 2007. Entrevista concedida a Mauro César Silveira.

CANAVILHAS, J. Webnoticia: propuesta de modelo periodístico parala WWW. Covilhã: Livros LabCom, 2007.

DÍAZNOCI,J.; PALACIOS.M. (Ed.). Ciberperiodismo: métodos de investigación. Una aproximación multidisciplinaren perspectiva comparada. Bilbao: Servicio Editorial de la Universidade del País Vasco, 2009a. Disponível em: <http://www.argitalpenak.ehu.es/p291-content/ es/contenidos/libro/se_indice_ciencinfo/es_ciencinf/ adjuntos/ciberperiodismo.pdf > . Acesso em: 30 jun. 2009.

(Ed.). Online journalism: research methods. A multidisciplinary approach in comparative perspective. Bilbao: Servicio Editorial de la Universidad del País Vasco, 2009b.

DÍAZ NOCI, J.; SALAVERRÍA, R. (Coord.). Manual de redacción ciberperiodística. Barcelona: Ariel, 2003.
FRANCO, M. Marcelo Franco: inédito. Buenos Aires: [s.n.], 2007. Entrevista concedida a Mauro César Silveira.

FIDLER, R. Mediamorfosis: comprender los nuevos medios. Buenos Aires: Granica, 1998.

HIGGINS, D. Horizons: the poetics and theory of the intermedia. Carbondale: Southern Illinois University Press, 1984.

IRIGOYEN, P. Pedro Irigoyen: inédito. Buenos Aires: [s.n.], 2007. Entrevista concedida a Mauro César Silveira.

LARRONDO URETA, A. El reportaje se reinventa en la red: estructura del reportaje hipertextual. Revista Latina de Comunicación Social, n. 57, 2004. Disponível em: $<$ www.ull.es/publicaciones/latina/20040357larrondo. htm>. Acesso em: 30 jun. 2009.

LONGHI, R. R. Os nomes das coisas: em busca do especial multimídia. In: CONGRESSO BRASILEIRO DECIÊNCIAS DA COMUNICAÇÃO-INTERCOM, 32., 2009, Curitiba. Anais... Curitiba: Intercom, 2009. Disponível em: <http://www.intercom.org.br/papers/ nacionais/2009/resumos/R4-1081-1.pdf>. Acesso em: 30 jun. 2009.

LONGHI, R. R. Infografia online: narrativa intermídia. In: ENCONTRO DA COMPÓS, 17., São Paulo. Anais... São Paulo: COMPÓS, 2008. Disponível em: <http:// www.compos.org.br/data/biblioteca_374.pdf $>$. Acesso em: 30 jun. 2009.

MACHADO, A. Arte e mídia. Rio de Janeiro:Zahar, 2007.

MASTRINI, G.;BECERRA, M. Periodistas y magnates: estructura y concentración de las industrias culturales en América Latina. Buenos Aires: Prometeo Editorial, 2006.

McADAMS, M. Flash Journalism: how to create multimedia news packages. Amsterdam: Elsevier, 2005.

PALACIOS, M. Ruptura, continuidade e potencialização no jornalismo on-line: o lugar da memória. In: MACHADO, E.; PALACIOS, M. (Org.). Modelos de jornalismo digital. Florianópolis: Calandra, 2003.

PINHEIRO, D. Pantagruel, o pingüim e a presidente. Revista Piauí, n. 22, p. 30-36, 2008.

PLAZA, J. Tradução intersemiótica. São Paulo: Perspectiva, 2001.

SALAVERRÍA, R. Redacción periodística en internet. Pamplona: EUNSA, 2005. 
SALAVERRÍA, R.; NEGREDO, S. Periodismo integrado: convergencia de medios y reorganización de redacciones. Barcelona: Sol90Media, 2008.

SANTORO, D. O matrimônio Kirchner, a imprensa e as eleições na Argentina. Austin: Knight Center for Journalism in the Americas, 2009. Entrevista concedida a Paul Alonso. Disponível em: <http://knightcenter. utexas.edu/blog/?q=pt-br/node/4426>. Acesso em: 27 jun. 2009.

SILVEIRA, M. C. Clarín.com e as possibilidades de convergência entre o jornalismo impresso e o jornalismo digital. Disponível em: <http://posjor.ufsc.br/ curso/projeto/512>. Acesso em: 30 jun. 2009.

Recebido: 28/12/2009

Received: $12 / 28 / 2009$

Aprovado: $25 / 03 / 2010$

Approved: 03/25/2010 